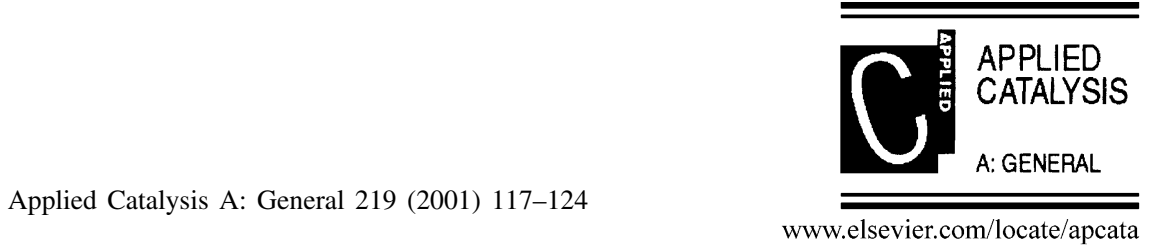

\title{
A novel boron nitride supported Pt catalyst for VOC incineration
}

\author{
Jeffrey C.-S. Wu ${ }^{\text {a,* }}$, Zhi-An Lin ${ }^{\mathrm{a}}$, Jen-Wei Pan ${ }^{\mathrm{a}}$, Min-Hon Rei ${ }^{\mathrm{b}}$ \\ a Department of Chemical Engineering, National Taiwan University, Taipei 10617, Taiwan, ROC \\ b Department of Chemical and Materials Engineering, Chang Gung University, Tao-Yuan 333, Taiwan, ROC
}

Received 22 January 2001; received in revised form 22 May 2001; accepted 25 May 2001

\begin{abstract}
Low-crystalline hexagonal boron nitride (h-BN) and $\gamma$-alumina supported Pt catalysts were employed to investigate the catalytic destruction of volatile organic compounds (VOC). The $0.3 \mathrm{wt} . \%$ Pt catalysts were prepared via incipient wetness method using $\mathrm{H}_{2} \mathrm{PtCl}_{6}$ as precursor. The oxidation of volatile gasoline was performed in a concentration of $2500 \mathrm{ppmv}$ with volume hour space velocity (VHSV) near $20000 \mathrm{~h}^{-1}$ from 100 to $500^{\circ} \mathrm{C}$. Instead of deactivation, the activity of Pt/h-BN increased significantly in the second run of the oxidation reaction. The light-off temperature (50\% conversion) decreased from 210 to $160-170^{\circ} \mathrm{C}$ in the second run of oxidation. Furthermore, $95 \%$ conversion was achieved at less than $200^{\circ} \mathrm{C}$. Meanwhile, the Pt/ $\gamma-\mathrm{Al}_{2} \mathrm{O}_{3}$ became deactivated in the second run of oxidation. The activity of $\mathrm{Pt} / \mathrm{h}-\mathrm{BN}$ was maintained for three temperature cycles. Long-term oxidation proved that Pt/h-BN activity did not decline over up to $80 \mathrm{~h}$. The positive binding energy shift from XPS revealed that a few boron oxide impurities contaminated on the h-BN surface, these provided the anchorage for the Pt clusters. Metallic Pt surface was oxidized to PtO during the initial oxidation, thus enhancing the oxidation activity. Based on irreversible $\mathrm{H}_{2}$ chemisorption, the platinum dispersion of $\mathrm{Pt} / \mathrm{h}-\mathrm{BN}$ were near $20 \%$ and did not change after oxidation at $500^{\circ} \mathrm{C}$. Metal sintering was minimal, owing to the high thermal conductivity of h-BN, which prevented any hot spots of oxidation on Pt sites. In sum, experimental results demonstrated that $\mathrm{Pt} / \mathrm{h}-\mathrm{BN}$ was a promising catalyst for VOC destruction. (C) 2001 Elsevier Science B.V. All rights reserved.
\end{abstract}

Keywords: Catalytic deep oxidation; Pt; Hexagonal BN; $\gamma$-Alumina; VOC; Gasoline

\section{Introduction}

Volatile organic compounds (VOC) are a primary air pollutant. A high temperature must be maintained for complete combustion of VOC to occur, and this can be costly as supplemental fuel is often required. In compliance with the stringent environmental regulations, catalytic oxidation can effectively destroy VOC. The advantage of low oxidation temperature is to reduce fuel consumption particularly for large volumes of

\footnotetext{
* Corresponding author. Tel.: +886-2-363-1994; fax: +886-2-362-3040.

E-mail address: cswu@ccms.ntu.edu.tw (J.C.-S. Wu).
}

dilute VOC polluted air. Supported Pt alumina or other metal oxides are conventional catalysts for such applications and have received broad attention [1].

Traditional metal oxide supports, such as $\mathrm{Al}_{2} \mathrm{O}_{3}$, $\mathrm{SiO}_{2}$, and zeolite possess rather low thermal conductivity and transform with water vapor at high temperature. The sintering of supported-metal may be severe on hot spots during the deep oxidation of VOC in highly exothermic reactions. The support characteristic also plays an important function in supported noble metal catalysts. Some metal-support interaction generally exists in most oxide-supported metal catalysts and brings about a negative influence on the catalytic activity [2]. Chloride is another negative impact on 
catalytic activity of noble metals by forming oxychloride. The species of $\mathrm{PtO}_{x} \mathrm{Cl}_{y}$ would suppress the oxidation activity substantially [3]. Generally, a noble metal is often dissolved in hydrogen chloride when it is employed as a precursor solution during catalyst preparation. Unfortunately, the elimination of chloride from traditional oxides is tedious. Therefore, one way to avoid these disadvantages would be the use of a non-oxide material as the support.

Our previous results reported that activated carbon supported Pt catalysts exhibited several advantages over the traditional $\mathrm{Pt} / \gamma$-alumina in VOC oxidation, such as hydrophobic surface, chlorine resistance and negligible metal-support interaction. The complete destruction of VOC was achieved at lower temperatures with activated carbon support than those with $\gamma$-alumina [4]. However, carbon support tends to be burned off if oxidation is carried out at high temperature (greater than $250^{\circ} \mathrm{C}$ ). In a continued search for non-oxide supports, we demonstrate a new non-oxide, hexagonal boron nitride (h-BN), as a support. The h-BN keeps the advantages of activated carbon without the weakness of being oxidized at high temperature. The h-BN has both crystalline and electronic structure similar to those of graphite, and possesses excellent chemical stability as well as high thermal conductivity. The h-BN is not attacked by water and any mineral acids except hydrogen fluoride, and in general, has been found to be very resistant to other kinds of chemical attack [5]. A particular advantage of h-BN is its extremely high thermal stability against volatilization up to $800^{\circ} \mathrm{C}$ in air [6]. The total oxidation of VOC employing h-BN supported Pt catalysts is investigated herein.

\section{Experimental}

\subsection{Catalysts preparation and characterization}

The h-BN powder was specially prepared and supplied by the High Performance Material Inc., Taiwan, ROC. The h-BN was calcined at a temperature of $800^{\circ} \mathrm{C}$, lower than the typical temperature of over $1000^{\circ} \mathrm{C}$ during synthesis. X-ray diffraction (XRD) spectra revealed that its crystallinity was low compared with that of typical h-BN. Another support, $\gamma$-alumina (Merck, USA) was chosen for comparison.
Platinum catalysts were prepared by an incipient wetness technique aiming for $0.3 \mathrm{wt} . \% \mathrm{Pt}$ with $\mathrm{h}-\mathrm{BN}$ and $\gamma$-alumina as supports designated as $\mathrm{Pt} / \mathrm{h}-\mathrm{BN}$ and $\mathrm{Pt} / \gamma-\mathrm{Al}_{2} \mathrm{O}_{3}$, respectively. Precursor salt, $\mathrm{H}_{2} \mathrm{PtCl}_{6} \cdot x \mathrm{H}_{2} \mathrm{O}$ purchased from Aldrich (USA), contained $\sim 40 \mathrm{wt} . \%$ of platinum. For better soaking on the hydrophobic h-BN support, methanol was chosen as the diluting solvent. The quantity of methanol required to completely fill the pore volume of support was predetermined. The amount of methanol-soluble Pt solution applied for the impregnation was typically from 95 to $100 \%$ of the absorptive capacity of support. The Pt concentration in solution was controlled to allow the total absorption by the support to achieve the desired $0.3 \mathrm{wt} . \%$ level of Pt in the catalyst. After impregnation, the catalysts were dried at ambient temperature overnight. All the catalysts were then reduced at $300^{\circ} \mathrm{C}$ for $1 \mathrm{~h}$, with a $3^{\circ} \mathrm{C} / \mathrm{min}$ rise from room temperature under a flow of $20 \% \mathrm{H}_{2}$ in $\mathrm{N}_{2}$ mixture, then stored in a desiccator for later use. The precise Pt loading of the catalysts was measured using the wet chemical method. Pt/h-BN was weighed, then rinsed and stirred in aqua regia. The leached solution was filtered and diluted with deionized water to the appropriate concentration. $\mathrm{Pt} / \gamma-\mathrm{Al}_{2} \mathrm{O}_{3}$ catalyst was dissolved in $\mathrm{HF}$ and aqua regia, then diluted with deionized water to the appropriate concentration. A series of standard Pt solutions (diluted from Aldrich platinum AA solution) were employed to establish calibration curves. The Pt concentration of solution was measured by UV adsorption at $261.8 \mathrm{~nm}$ [7], the percentage weight of Pt loading was then calculated. The Pt dispersion was estimated from the irreversible $\mathrm{H}_{2}$ chemisorption [8].

Temperature programmed reduction (TPR) was performed on both Pt catalysts. Fresh catalyst $(0.2 \mathrm{~g})$ was first oxidized under an air flow at $300^{\circ} \mathrm{C}$ for $2 \mathrm{~h}$, cooled to near $50^{\circ} \mathrm{C}$, purged with Ar, then switched to a $5 \% \mathrm{H}_{2} / \mathrm{Ar}$ flow and the temperature was increased to $650^{\circ} \mathrm{C}$ with a heating rate of $10^{\circ} \mathrm{C} / \mathrm{min}$. The specific surface area of catalyst was calculated from the $\mathrm{N}_{2}$ adsorption at $77 \mathrm{~K}$. Transmission electron microscopy (TEM) and scanning electron microscopy (SEM) were employed to examine the morphology of the catalysts. The crystallinity was analyzed by XRD. X-ray photoelectron spectroscopy (XPS) was conducted on a MicroTech MT500 instrument. The spectrometer vacuum was in the $10^{-9}$ Torr range. The hemispherical analyzer was operated in the fixed retarded ratio near 


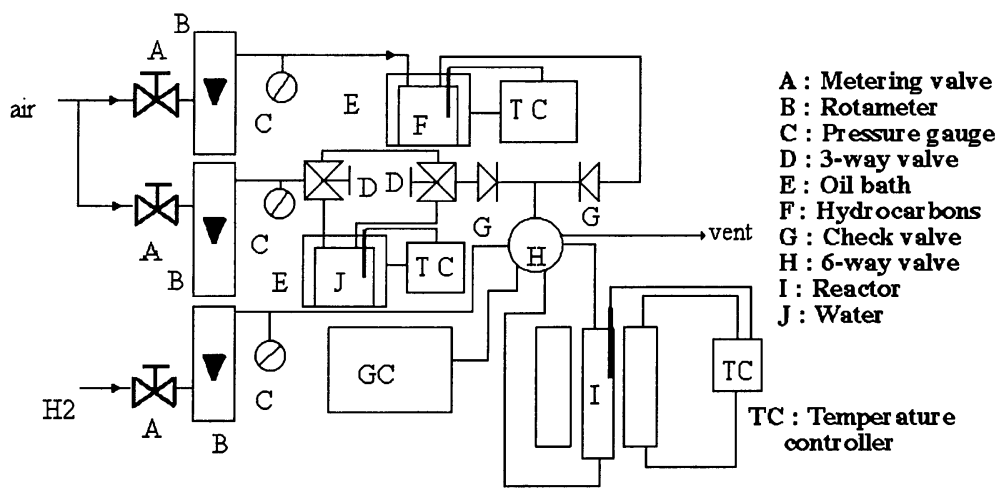

Fig. 1. Schematic of reactor system.

11. $\mathrm{Mg} \mathrm{K} \alpha$ radiation $(h v=1253.6 \mathrm{eV})$ was used as $\mathrm{X}$-ray source. Catalyst (in powder form) was affixed onto the sample holder by silver glue. Silver $\left(3 \mathrm{~d}_{5 / 2}\right.$, $368.3 \mathrm{eV})$ and carbon $(1 \mathrm{~s}, 284.5 \mathrm{eV})$ were used as an internal standard for binding energy calibration.

\subsection{Catalytic oxidation}

The unleaded octane 95 gasoline was purchased from a gas station of China Petroleum Corporation (CPC), Taiwan, ROC. This gasoline has a specification of about $35 \mathrm{vol} \%$ of aromatics. Reagent-grade iso-hexane purchased from Alps Chemical Co. (Taiwan, ROC) was used to represent one of the major components of gasoline vapor. Fig. 1 depicts the schematic of reactor system. An air stream, which bubbled through a saturator filled with liquid hydrocarbon carried the volatile vapor. The concentrations was regulated by the temperature of the saturator and was mixed with an additional air stream. The concentrations of gasoline vapor and iso-hexane were 2500 and $600 \mathrm{ppmv}$, respectively, and they were always confirmed by gas chromatography (GC) before the reaction. The reactions were performed at temperatures ranging from 90 to $500^{\circ} \mathrm{C}$ under atmospheric pressure. The catalyst $(0.3 \mathrm{~g})$ was charged in the middle of a straight-tube Pyrex reactor with a $16 \mathrm{~mm}$ i.d. A thermocouple was placed in the center of the catalyst bed to record reaction temperature and also to control the furnace temperature. In several experiments, the catalyst was pretreated to $300^{\circ} \mathrm{C}$ for $2 \mathrm{~h}$ then cooled to room temperature in air or nitrogen before switching to reactant stream. The reactant flows were tuned to a volume hour space velocity (VHSV) of $20000 \mathrm{~h}^{-1}$. Since $\gamma$-alumina is denser than $\mathrm{h}-\mathrm{BN}$, the reactant flow rate was reduced accordingly for the same VHSV to be maintained within $\mathrm{Pt} / \gamma-\mathrm{Al}_{2} \mathrm{O}_{3}$. The reaction temperature usually was increased from low to high, and was decreased again to low temperature in some cases to check consistency. Typically, an accumulated run time lasted nearly $30 \mathrm{~h}$ per catalyst. An on-line HP6890 GC equipped with thermal conductivity detector (TCD) and flame ionization detector (FID) in series measured both reactants and products. Separation of $\mathrm{H}_{2} \mathrm{O}, \mathrm{CO}_{2}$ and most light hydrocarbons was accomplished with an HP-PLOT Q $30 \mathrm{~m}$ capillary column. The primary oxidation products were found to be $\mathrm{CO}_{2}$ and $\mathrm{H}_{2} \mathrm{O}$ only. That is, under experimental conditions carbon monoxide and other partial oxidation products were virtually undetectable. Thus, the conversion was calculated based on the total hydrocarbon remaining after oxidation. The carbon balance between reactants and products were assessed and the maximum difference was within $10 \%$. The conversion was calculated based upon the total carbon as gasoline volatile is a mixture. A blank test was conducted using h-BN without $\mathrm{Pt}$ loading. No activity was observed up to $250^{\circ} \mathrm{C}$.

\section{Results and discussion}

\subsection{Characteristics of catalysts}

Table 1 lists the specific surface areas of supports both before and after VOC oxidation. The initial surface area of h-BN and $\gamma-\mathrm{Al}_{2} \mathrm{O}_{3}$ are 70 and $99 \mathrm{~m}^{2} / \mathrm{g}$, 
Table 1

Properties of Pt catalyst

\begin{tabular}{|c|c|c|c|}
\hline Catalysts & $\begin{array}{l}\text { Fresh } \\
\left(\mathrm{m}^{2} / \mathrm{g}\right)\end{array}$ & $\begin{array}{l}\text { VOC oxidation }{ }^{\mathrm{a}} \\
\left(\mathrm{m}^{2} / \mathrm{g}\right)\end{array}$ & $\begin{array}{l}\text { Average particle } \\
\operatorname{size}^{b}(\mu \mathrm{m})\end{array}$ \\
\hline $\mathrm{Pt} / \mathrm{h}-\mathrm{BN}$ & 70 & 69 & 10 \\
\hline $\mathrm{Pt} / \gamma-\mathrm{Al}_{2} \mathrm{O}_{3}$ & 99 & 84 & 180 \\
\hline
\end{tabular}

${ }^{\text {a }}$ VOC oxidation: $2500 \mathrm{ppmv}$ gasoline vapor in air up to $500^{\circ} \mathrm{C}$.

${ }^{\mathrm{b}}$ Average particle size measured by laser scattering (Coulter LS230).

respectively. Generally the surface area of crystalline h-BN is very low (e.g. $1-2 \mathrm{~m}^{2} / \mathrm{g}$ ). The high surface area of our h-BN was due to the low processing temperature according to supplier, which in turn prevented it from transforming to high crystallinity during synthesis. Fig. 2a and $\mathrm{b}$ display the SEM and TEM micrographs of $h-B N$ and $\mathrm{Pt} / \mathrm{h}-\mathrm{BN}$, respectively. The h-BN particles appear flaky and have an irregular shape. A few Pt clusters, 5-15 nm in size, were observed in TEM micrograph.

The potential loss of $\mathrm{Pt}$ on $\mathrm{Pt} / \mathrm{h}-\mathrm{BN}$ during reaction may be attributed to weak binding between metal and h-BN which has low surface energy. Table 2 lists the accurate Pt loading measured from wet chemical analysis as well as the dispersion from irreversible $\mathrm{H}_{2}$ chemisorption. The Pt loadings nearly achieved the intended value, i.e. $0.3 \mathrm{wt} . \%$, in preparation using incipient wetness technique. For fresh hydrogen reduced catalysts, the dispersion of $\mathrm{Pt} / \mathrm{h}-\mathrm{BN}$ and $\mathrm{Pt} / \gamma-\mathrm{Al}_{2} \mathrm{O}_{3}$ were 19 and $30 \%$, respectively. The variation of $\mathrm{Pt}$ dispersion could be due to the diverse specific surface areas among supports (Table 1). The Pt loading and dispersion remained unchanged after oxidation. Fig. 3 shows the XPS of two h-BNs. When compared with that of a standard highly crystalline hexagonal $\mathrm{BN}$, the binding energy of h-BN indicates a positive $0.7 \mathrm{eV}$ shift. Being calcined at lower temperature, our h-BN may have residual $\mathrm{B}-\mathrm{O}$ bonds which induce a positive binding energy shift. The residual $\mathrm{B}-\mathrm{O}$ bond provides

Table 2

Platinum loading and dispersion of catalysts

\begin{tabular}{lllll}
\hline Catalysts & $\begin{array}{l}\text { Fresh } \\
\text { (wt.\%) }\end{array}$ & \multicolumn{2}{l}{$\begin{array}{l}\text { Dispersion VOC oxidation } \\
(\%)\end{array}$} & $\begin{array}{l}\text { Dispersion } \\
(\%)\end{array}$ \\
\hline $\mathrm{Pt} / \mathrm{h}-\mathrm{BN}$ & 0.30 & 19 & 0.29 & 19 \\
$\mathrm{Pt} / \boldsymbol{\gamma}-\mathrm{Al}_{2} \mathrm{O}_{3}$ & 0.29 & 30 & 0.28 & 29 \\
\hline
\end{tabular}

${ }^{\text {a }}$ VOC oxidation: $2500 \mathrm{ppmv}$ gasoline vapor in air up to $500^{\circ} \mathrm{C}$.

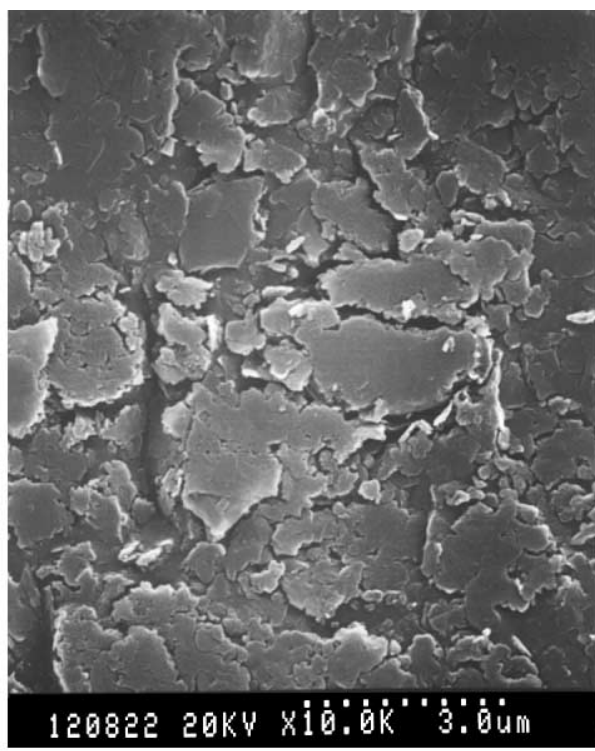

(a)

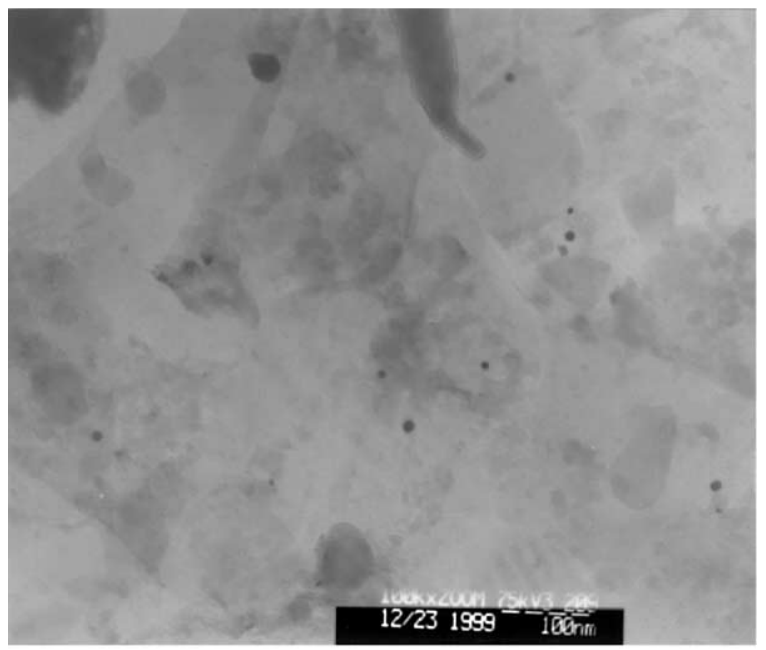

(b)

Fig. 2. (a) SEM of h-BN; (b) TEM of $P t / h-B N$.

an excellent anchor for Pt cluster, thus preventing $\mathrm{Pt}$ loss during catalytic oxidation.

\subsection{VOC deep oxidation}

Generally, depending upon its source, the volatile compounds from gasoline consist of a $\mathrm{C}_{4}-\mathrm{C}_{7}$ mixture, which includes paraffins, olefins and aromatics. 


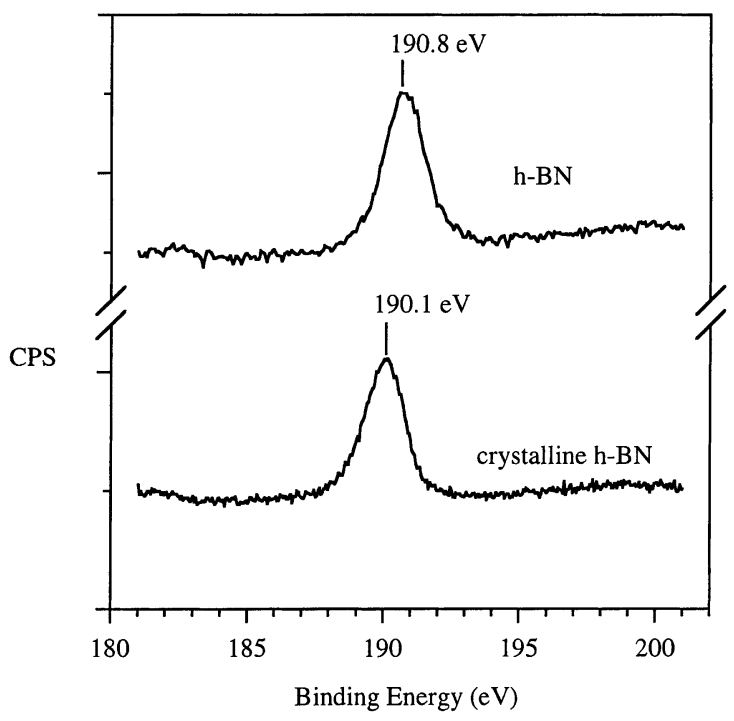

Fig. 3. XPS B 1s of h-BN.

GC/mass analysis of CPC gasoline vapor disclosed that its primary components were iso-pentane and iso-hexane, and its minor components included $\mathrm{C}_{4}$ isomers, benzene and toluene. Fig. 4 shows the temperature dependencies of iso-hexane oxidation on $\mathrm{Pt} / \mathrm{h}-\mathrm{BN}$ and $\mathrm{Pt} / \gamma-\mathrm{Al}_{2} \mathrm{O}_{3}$, respectively. Fig. 5 depicts the oxidation results of the gasoline volatile on

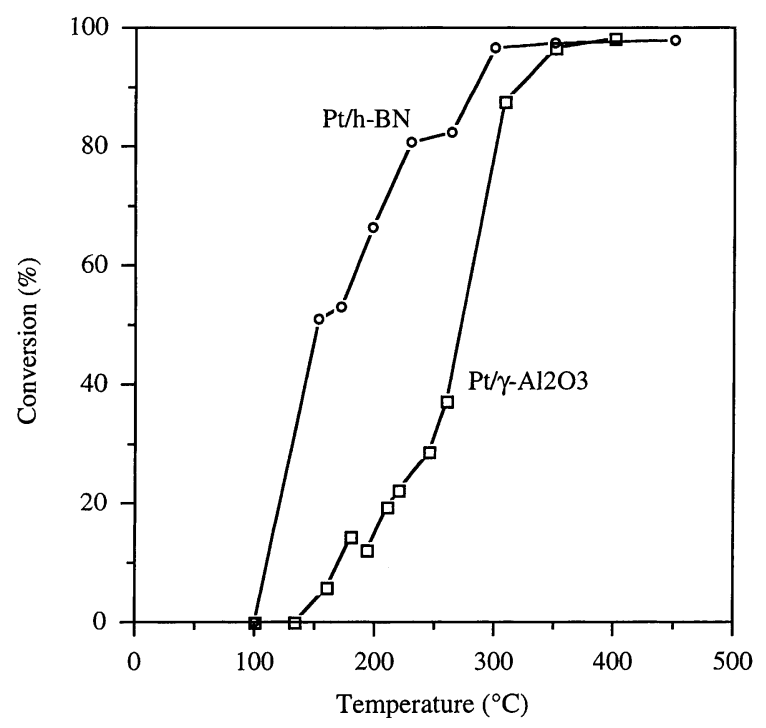

Fig. 4. Oxidation of iso-hexane $(600 \mathrm{ppmv})$ on $\mathrm{Pt} / \mathrm{h}-\mathrm{BN}$ and $\mathrm{Pt} / \gamma-\mathrm{Al}_{2} \mathrm{O}_{3}$.

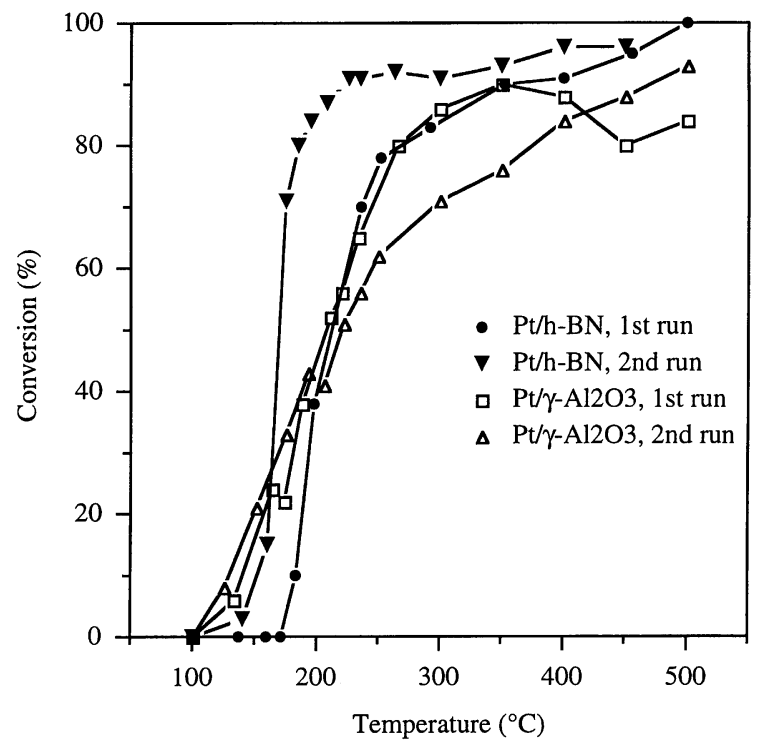

Fig. 5. Oxidation of gasoline vapor on $\mathrm{Pt} / \mathrm{h}-\mathrm{BN}$ and $\mathrm{Pt} / \gamma-\mathrm{Al}_{2} \mathrm{O}_{3}$.

$\mathrm{Pt} / \mathrm{h}-\mathrm{BN}$ and $\mathrm{Pt} / \gamma-\mathrm{Al}_{2} \mathrm{O}_{3}$, respectively. As shown in Figs. 4 and 5, the activity of $\mathrm{Pt} / \mathrm{h}-\mathrm{BN}$ was superior to that of $\mathrm{Pt} / \gamma-\mathrm{Al}_{2} \mathrm{O}_{3}$. In addition, the light-off temperature $\left(50 \%\right.$ conversion) of $\mathrm{Pt} / \mathrm{h}-\mathrm{BN}$ was $170^{\circ} \mathrm{C}$, while that of $\mathrm{Pt} / \gamma-\mathrm{Al}_{2} \mathrm{O}_{3}$ was approximately $260^{\circ} \mathrm{C}$. Similar results were also found for the oxidation of gasoline vapor. In Fig. 5, initially the activities of $\mathrm{Pt} / \mathrm{h}-\mathrm{BN}$ and $\mathrm{Pt} / \gamma-\mathrm{Al}_{2} \mathrm{O}_{3}$ were not noticeably distinguished and the light-off temperatures were near $210^{\circ} \mathrm{C}$. After the reactor was cooled to room temperature, the second run reaction was re-started and the temperature increased to $500^{\circ} \mathrm{C}$. During the second run reaction, both catalysts showed a significant difference. The light-off temperature of $\mathrm{Pt} / \mathrm{h}-\mathrm{BN}$ decreased to near $170^{\circ} \mathrm{C}$ and the oxidation quickly attained a conversion greater than $95 \%$ at $220^{\circ} \mathrm{C}$, while the activity of $\mathrm{Pt} / \gamma-\mathrm{Al}_{2} \mathrm{O}_{3}$ declined. The light-off temperature of $\mathrm{Pt} / \gamma-\mathrm{Al}_{2} \mathrm{O}_{3}$ escalated slightly to $220^{\circ} \mathrm{C}$, and temperatures greater than $500^{\circ} \mathrm{C}$ were required to achieve $90 \%$ conversion. While near complete oxidation of iso-hexane was achieved at $300^{\circ} \mathrm{C}$ with $\mathrm{Pt} / \mathrm{h}-\mathrm{BN}$ catalyst and at $350^{\circ} \mathrm{C}$ with $\mathrm{Pt} / \gamma-\mathrm{Al}_{2} \mathrm{O}_{3}$ catalyst (Fig. 4), only about $90 \%$ of gasoline vapor was oxidized at the similar temperatures with these two catalysts, respectively (Fig. 5). Complete oxidation of gasoline vapor was obtained only after the reaction temperature was raised to over $450^{\circ} \mathrm{C}$ in $\mathrm{Pt} / \mathrm{h}-\mathrm{BN}$. Conceivably the demand for 


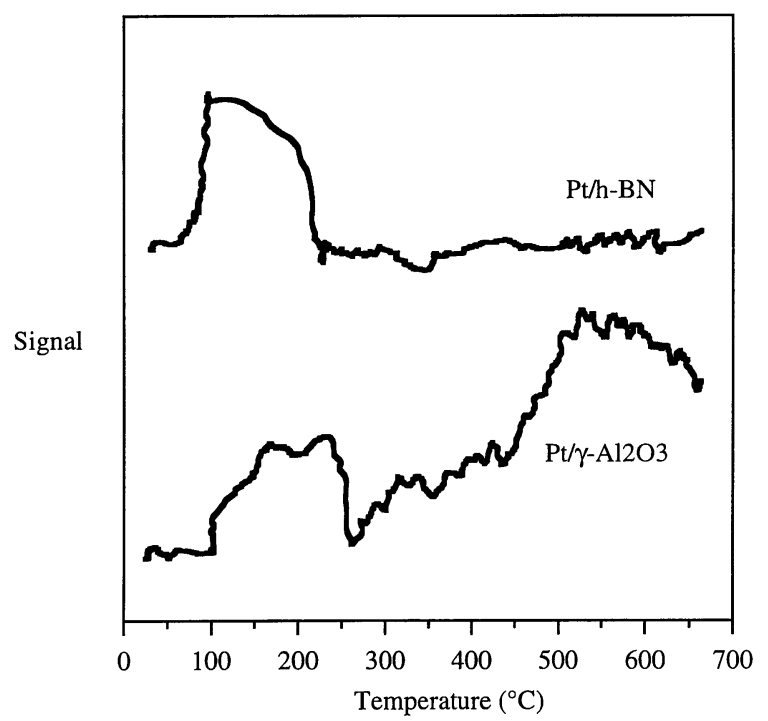

Fig. 6. TPR of Pt/h-BN and $\mathrm{Pt} / \boldsymbol{\gamma}-\mathrm{Al}_{2} \mathrm{O}_{3}$.

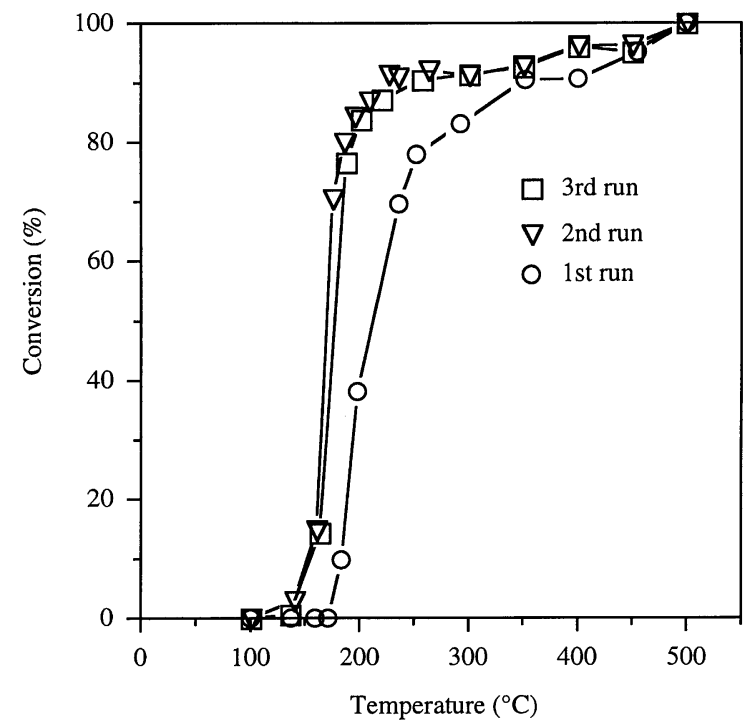

Fig. 7. The oxidation of gasoline vapor on $\mathrm{Pt} / \mathrm{h}-\mathrm{BN}$.

at $500^{\circ} \mathrm{C}$, which substantially reduces Pt activity [10]. Völter et al. found that metallic Pt were more active than Pt oxide complex in the oxidation of $n$-heptane [3]. Our support, h-BN, other than residual $\mathrm{B}-\mathrm{O}$ bonds, virtually has no interaction with Pt. Moreover, akin to graphite, the benzene-like structure of h-BN may act as an electron donor to facilitate oxygen chemisorption by the Pt atom. During VOC oxidation, the surface of metallic $\mathrm{Pt}$ is covered either by $\mathrm{PtO}$ or chemisorbed oxygen, which are both highly reactive for oxidation. Therefore, the activity of $\mathrm{Pt} / \mathrm{h}-\mathrm{BN}$ is higher than that of $\mathrm{Pt} / \gamma-\mathrm{Al}_{2} \mathrm{O}_{3}$.

The activity duration of $\mathrm{Pt} / \mathrm{h}-\mathrm{BN}$ was further investigated to explain the increasing activity in the second run of oxidation. Fig. 7 depicts the oxidation of $\mathrm{Pt} / \mathrm{h}-\mathrm{BN}$ for two additional cycles. Notably, the activity was well maintained during the third run. The results indicated that, after the first oxidation, the Pt surface became more active, then was preserved thereafter. Fig. 8 displays the pretreatment effect in the oxidation activity. In order to distinguish either the thermal or oxidative effect, one of two kinds of pretreatment, $\mathrm{N}_{2}$ or air at $300^{\circ} \mathrm{C}$, was applied to the fresh catalysts prior to gasoline vapor oxidation, respectively. The catalyst of pretreatment in air gave the light-off temperature of approximately $170^{\circ} \mathrm{C}$ and attained $90 \%$ conversion near $200^{\circ} \mathrm{C}$. They were very similar to the results of the 


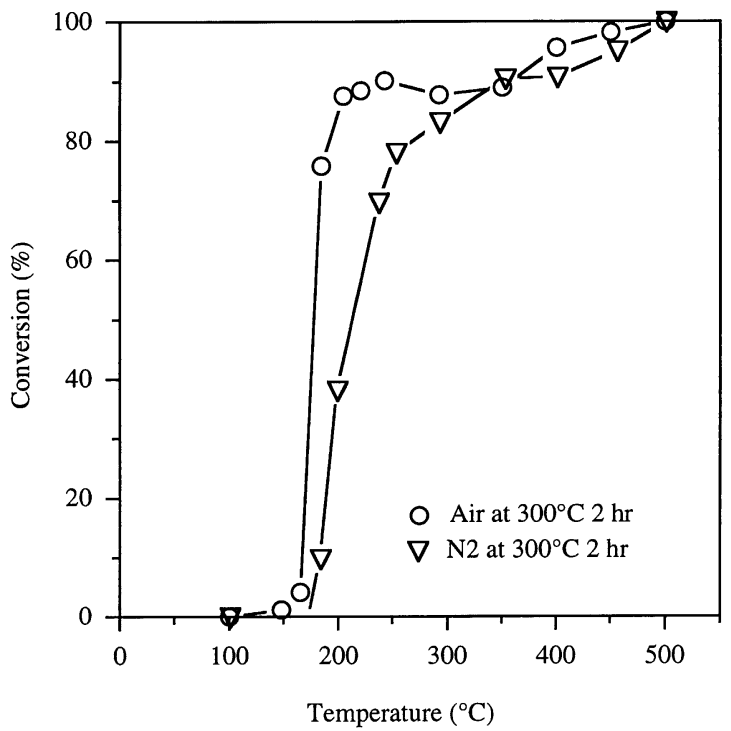

Fig. 8. The effect of pretreatment on the activity of gasoline oxidation of $\mathrm{Pt} / \mathrm{h}-\mathrm{BN}$.

second run in Fig. 7. The $\mathrm{Pt} / \mathrm{h}-\mathrm{BN}$ with pretreatment in $\mathrm{N}_{2}$ gave low initial activity. Thermal $\mathrm{N}_{2}$ treatment cannot assist the $\mathrm{PtO}$ formation, thus yielding low initial activity. Therefore, in the second run of oxidation, that $\mathrm{Pt} / \mathrm{h}-\mathrm{BN}$ gave better activity than the first run was due to cleaner surface of Pt cluster as well as the formation of active $\mathrm{PtO}$ species during the VOC oxidation.

The anchorage of $\mathrm{Pt}$ on the h-BN surface via residual $\mathrm{B}-\mathrm{O}$ bonds may not be as strong as that on $\gamma-\mathrm{Al}_{2} \mathrm{O}_{3}$. However, the experimental results in Tables 1 and 2 indicate that $\mathrm{h}$-BN provides a moderate surface area, which can accommodate the $\mathrm{Pt}$ cluster and maintain its dispersion without sintering after oxidation reaction.

The life span of a catalyst is crucial for its industrial application. Fig. 9 demonstrates the long-term stability comparison of $\mathrm{Pt} / \mathrm{h}-\mathrm{BN}$ and $\mathrm{Pt} / \gamma-\mathrm{Al}_{2} \mathrm{O}_{3}$. The oxidation was maintained at $185^{\circ} \mathrm{C}$ to study the deactivation of catalysts. Within $2 \mathrm{~h}$, the conversions were quickly increased to 90 and $72 \%$ in $\mathrm{Pt} / \mathrm{h}-\mathrm{BN}$ and $\mathrm{Pt} / \gamma-\mathrm{Al}_{2} \mathrm{O}_{3}$, respectively. The activity of the former was well sustained for $80 \mathrm{~h}$, and showed no sign of deactivation. In fact, the conversion was slightly increased to $95 \%$ at the end of $80 \mathrm{~h}$. In contrast, the conversion of $\mathrm{Pt} / \gamma-\mathrm{Al}_{2} \mathrm{O}_{3}$ began to decrease after $15 \mathrm{~h}$, then gradually reduced to less than $60 \%$. A less

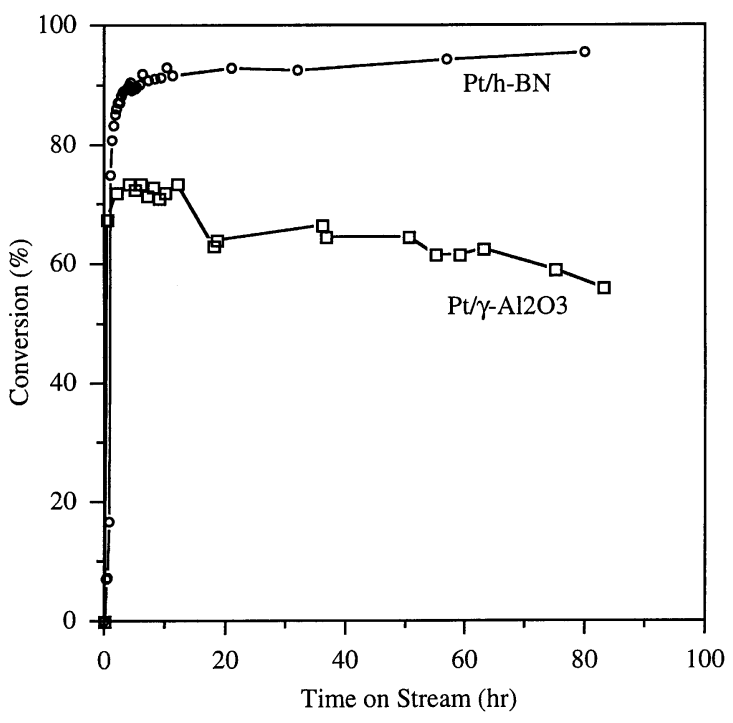

Fig. 9. The oxidation of gasoline vapor on $\mathrm{Pt} / \mathrm{h}-\mathrm{BN}$ and $\mathrm{Pt} / \gamma-\mathrm{Al}_{2} \mathrm{O}_{3}$ at $185^{\circ} \mathrm{C}$.

active oxidic surface complex $\mathrm{Pt}^{\mathrm{IV}}$ might be formed on the alumina surface resulting in the deactivation of $\mathrm{Pt} / \gamma-\mathrm{Al}_{2} \mathrm{O}_{3}$ [3] while no such effect occurred on h-BN surface. Although the apparent reaction temperature was only $185^{\circ} \mathrm{C}$, the real temperature of local $\mathrm{Pt}$ site was likely much higher. The thermal conductivity of h-BN is higher than that of $\gamma$-alumina [11]. The $\mathrm{Pt}$ sintering may be minimized due to the elimination of hot spots on catalysts during deep oxidation.

The aforementioned findings indicate that h-BN provided a superior support for Pt in deep VOC oxidation. Unlike $\gamma$-alumina, there are virtually no acid sites on h-BN, thus the activity loss due to coking can be minimized. An additional advantage of h-BN is its high-temperature potential (greater than $800^{\circ} \mathrm{C}$ ) because there is no phase transformation phenomenon as occurs with $\gamma-\mathrm{Al}_{2} \mathrm{O}_{3}$ or other oxides. Consequently, several undesirable factors affecting the traditional oxide support, such as coking and metal-support interaction, are absent and would not deactivate $\mathrm{Pt} / \mathrm{h}-\mathrm{BN}$ catalyst.

\section{Conclusion}

This study showed the favorable findings of VOC incineration employing h-BN supported Pt catalysts. 
The light-off temperature of gasoline vapor was as low as $170^{\circ} \mathrm{C}$. The oxidation conversion achieved more than $90 \%$ near $200^{\circ} \mathrm{C}$. Furthermore, Pt/h-BN activities can be maintained and endure longer than those of traditional $\mathrm{Pt} / \gamma-\mathrm{Al}_{2} \mathrm{O}_{3}$. Notably, boron nitride exhibits superior properties, which include chemical inertness, thermal stability, thermal conductivity and minimum metal-support interaction. Low crystalline $\mathrm{h}-\mathrm{BN}$ provides a moderate surface area that can accommodate dispersed phase noble metals, while still preserves the unique characteristics. Boron nitride is a promising support for catalysts. The use of h-BN will become a frontier in catalysis.

\section{Acknowledgements}

The authors would like to thank the National Science Council, Taiwan, ROC and China Petroleum Corporation for financially supporting this research under the project numbers NSC 89-2214-E-002-020 and NSC 88-CPC-E-002-019, respectively.

\section{References}

[1] J.J. Spivey, Ind. Eng. Chem. Res. 26 (1987) 2165-2180.

[2] H.C. Yao, M. Sieg, H.K. Plummer Jr., J. Catal. 59 (1979) 365-374.

[3] J. Völter, G. Lietz, H. Spindler, H. Lieske, J. Catal. 104 (1987) 375-380.

[4] J.C.S. Wu, Z.A. Lin, F.M. Tsai, J.W. Pan, Catal. Today 63 (2000) 419-426.

[5] K. Niedenzu, J.W. Dawson, Boron Nitride, Boron-Nitrogen Compounds, Springer, Berlin, 1965 (Chapter 6).

[6] C.G. Cofer, J. Econ., Carbon 33 (4) (1995) 389-395.

[7] C. Prado-Burguete, A. Linares-Solano, F. Rodríguez-Reinoso, C. Salinas-Martínez De Lecea, J. Catal. 128 (1991) 397-404.

[8] M.B. Palmer Jr., M.A. Vannice, J. Chem. Tech. Biotechnol. 30 (1980) 217-224.

[9] G. Veser, M. Ziauddin, L.D. Schmidt, Catal. Today 47 (1999) 219-228.

[10] C.-P. Hwang, C.-T. Yeh, J. Catal. 182 (1999) 48-55.

[11] H. Sumiya, S. Sato, S. Yazu, US Patent 5,332,629 (26 May 1994). 